\title{
The Complexity Analysis in Dual-Channel Supply Chain Based on Fairness Concern and Different Business Objectives
}

\author{
Li Qiu-xiang $\mathbb{D},{ }^{1}$ Zhang Yu-hao $(\mathbb{D})^{2}$ and Huang Yi-min $\mathbb{I D}^{3}$ \\ ${ }^{1}$ Institute of Management Science and Engineering, Henan University, Kaifeng 475004, China \\ ${ }^{2}$ School of Business, Henan University, Kaifeng 475004, China \\ ${ }^{3}$ School of Management \& Economics, North China University of Water Resources and Electric Power, Zhengzhou 450046, China
}

Correspondence should be addressed to Zhang Yu-hao; zyhydcg@163.com and Huang Yi-min; huang800526@163.com

Received 6 December 2017; Accepted 11 April 2018; Published 20 May 2018

Academic Editor: Carlos Gershenson

Copyright (C) 2018 Li Qiu-xiang et al. This is an open access article distributed under the Creative Commons Attribution License, which permits unrestricted use, distribution, and reproduction in any medium, provided the original work is properly cited.

\begin{abstract}
We study a dual-channel supply chain which consists of one dual-channel manufacturer and one traditional retailer considering fairness concern. The manufacturer takes the market share as one of its business objectives in the competition game. We are devoted to establishing a vertical Nash game model and analyzing the price evolution of the model via the method of complexity theory and take adaptive adjustment control method to control the system's chaotic state. The results show that an excessive price adjustment speed will hurt the system's stability as well as profit of the supply chain. A high level fair caring for retailer will push the system to fall into chaos earlier, while a higher level fair caring for manufacturer will enlarge the stability region of the system. Setting the different objectives by the manufacturer will cause drastic competition in dual-channel supply chain. The research of this paper is of great significance to the decision-makers' price decision and supply chain operation management.
\end{abstract}

\section{Introduction}

Nowadays, because of the Internet technology, e-ecommerce is developing rapidly in China. More and more online direct channels are established by many manufacturers and retailers. Compared with the traditional sale channels, the online direct channel not only can reduce operation cost but also provides high quality products, and this way consumers can choose the best way that provides commodity with the most convenience and the largest discount [1].

A significant amount of research has been done on dualchannel supply chain. Some scholars studied the influence of channel structure on participants. For example, $\mathrm{Ma}$ and Xie [2] considered one manufacturer and one retailer in a dual-channel supply chain, the manufacturer holds either asymmetric or symmetric channel power compared to the retailer. The result found that the system stability should be easier to maintain with asymmetric channel power. $\mathrm{Lu}$ and Liu [3] compared the single and dual-channel distribution systems considering the effect of e-commerce channel. The results showed that if the e-channel efficiency was low adequately, the e-commerce channel might dominate the distribution systems. Cai [4] investigated the influence of channel structure and channel coordination on the supplier, the retailer, and the entire supply chain in the context of two single-channel and two dual-channel supply chains. He suggested that the preference of the supplier and the retailer over channel structures with and without coordination is different.

The literatures on price strategies as well as channel structures in supply chain were studied extensively. Chen and Wang [5] studied smart phone supply channel selection in different power structures; they pointed out that the firm who has higher channel power will gain more profit. Liu and $\mathrm{Xu}$ [6] proved that dual-channel collaborative pricing enabled avoiding risk effectively. Gao et al. [7] established three price models on dual-channel closed-loop supply chain; the results showed that when customer's acceptance with the Internet channel increases, the wholesale price and retail price would decrease, while the optimal recycling transfer price was not affected. Huang and Swaminathan [8] studied four prevalent pricing strategies which differed in the autonomy degree for 
the Internet channel. Xu et al. [9] investigated the influence of coordinating contract on a dual-channel supply chain and analyzed retailer's price decision.

The literature above studied dual-supply chain from channel structure and price strategies aspects. However, they did not consider the influence of behavior features of decision-makers on the channel structure and price strategies.

As a matter of fact, the firms will have different business objectives for achieving maximum profit and expanding market shares at the same time, especially in the oligarchic market.

The interest in market-share analysis has always received more attention by scholars. Bell et al. [10] studied the relation between market share and marketing effort; they pointed out that market share equals marketing effort divided by total marketing effort when some assumptions were satisfied. Carpenter et al. [11] have expressed the relationship of profitability and market share. Szymanski et al. [12] performed a meta-analysis on market-profitability; the result showed that, on average, market share has a positive effect on business profitability. Dutta and King [13] studied the market share, profitability, and other business objectives simultaneously. $\mathrm{Li}$ and $\mathrm{Ma}$ [14] considered the fact that the manufacturer and retailer have different business objectives with bounded rationality and analyzed the system characteristic through the theory of bifurcations and simulation. The results showed that different business objectives and competition can expand the stability region of Nash equilibrium.

Fairness concern is another important behavior factor that enterprises pay attention to. The studies about fairness concern showed that it has significant influence on price strategies and efficiency of supply chain. Some scholars studied fairness concerns in the single-channel. Cui et al. [15] showed that when fairness is concerned by supply chain members, the manufacturer tends to make simple wholesale price contract to coordinate the supply chain rather than to elaborate one. Pavlov and Katok [16] extended the research on channel coordination by developing a new model based on fairness and bounded rationality to explain rejections. Katok et al. [17] studied the performance of wholesale price when the supply chain partners' fairness concerns were private information. They found that wholesale pricing could coordinate the supply chain when fairness concerns were strong enough. Du et al. [18] studied the influence of retailer's fairness concerns on the coordination of supply chain and found that the fairness of retailer cannot change the coordination condition of the supply chain. Some scholars also analyzed fairness in dual-supply chain. Zhang and Ma [19] established two different pricing policies in a dual-supply chain with a fair caring retailer and showed that the higher adjustment speed of the direct price was disadvantageous to manufacturer but good for the retailer. Q. $-\mathrm{H}$. Li and B. $\mathrm{Li}$ [20] considered the fact that the retailer had fairness concerns in the dual-channel supply chain with the services. The result pointed out that channel efficiency would decrease with the increase of the retailer's fairness level. Wang et al. [21] discussed the coordination of a dual-channel supply chain considering a fair caring retailer and developed a Stackelberg game between manufacture and retailer and pointed out that the retailer's fairness concern is beneficial to improve its own utility, but it damages the profits of manufacturer. Zhang and Wang [22] examined the influence of a firm's horizontal and vertical fairness concerns on the three-party supply chain coordination in a duopoly supply chain game model. They found that a firm's horizontal fairness concern would generate direct influence on its own traditional channel wholesale price and demand, and a firm's vertical fairness concern, under equilibrium, will generate direct influence on its online channel equilibrium price and demand.

Some researchers center on the dynamic characteristics of model in dual-supply chain. Rand [23] found that with the adjustment process of Cournot, the Nash equilibrium might loss stability and chaotic dynamics occurs. Puu [24] pointed out that strange attractors could appear in the duopoly model and briefly analyzed three oligopoly competition conditions. Moreover, he reconsidered whether the equilibrium remains stable with an increasing number of firms in [25]. Sun and Ma [26] analyzed bifurcation and cyclic attractors in Cournot duopoly game model. $\mathrm{Li}$ and $\mathrm{Ma}$ [27] established a Bertrand model based on nonlinear demand functions in Chinese cold rolled steel market. They found that the system's parameters could affect the stability of Nash equilibrium point and made the system go into chaos. Ma and Wang [28] considered a dual-channel retailer who made delay decision, and showed that adopting price delay strategy in traditional channel would make the system more stable, while adopting price delay decision in network channel would make the system less stable. $\mathrm{Li}$ and $\mathrm{Ma}$ [29] considered a closed-loop supply chain (CLSC) with product recovery and found that improving the retailer's competitive position made the CLSC system get into chaos easier. Huang et al. [30] considered the fact that the customer had risk aversion behavior for probabilistic product and analyzed the influences of parameters on the system stability nonlinear science. Zheng et al. [31] developed three dynamic game models to investigate the influences of parameters on the stability of risk-averse complementary product manufacturer. $\mathrm{Li}$ et al. [32] analyzed the dynamics of dual-channel energy supply chain model with heterogeneous retailers and showed that the adjustment speed of price has obvious impact on the complexity of competition. Matouk et al. [33] established a nonlinear quadropoly game based on Cournot model, fully heterogeneous, and analyzed the stability of discrete-time dynamical system and discussed the Neimark-Sacker bifurcation. Wu and Van Gorder [34] studied dynamic multipleplayer multiple-level discrete-time leader-followers games in the vein of Cournot or Stackelberg games under incomplete information and complete information. The results found that under perfect information players tended to quickly converge upon their respective equilibrium values, while incomplete information could result in loss of regularity and the emergence of periodic or chaotic dynamics. The papers mentioned above provided many methods and perspectives with analyzing the complex characteristic of the supply chain.

However, we can hardly find few papers that simultaneously considered fairness concerns and different business objectives of the manufacturer and retailer in dual-channel 
supply chain as well as investigating the stability and complexity features of the system with different parameters values combination.

In this paper, we considered a fair caring manufacturer concern about its market share and a fair caring retailer in the dual-cannel supply chain. Then, a vertical Nash game model was developed; meanwhile the complex dynamic behaviors of the system were explored under different parameters conditions by chaos theory, such as chaos, chaotic attractors, $2 \mathrm{D}$ period diagram, and sensitivity dependence to initial conditions.

The paper is organized as follows. In Section 2, the model assumptions and notations were described. The model analysis of the system is shown in Section 3. In Section 4, numerical simulations are presented. Chaos control of the system is adopted in Section 5. Conclusions are drawn in Section 6 .

\section{Model Assumptions and Model Construction}

The model we have made is based on the following assumptions:

(a) The linear demand functions were taken to describe consumer demand.

(b) $w$ is wholesale price from manufacturer to retailer for per unit goods; the marginal cost of the product is $c$ and $w>$ c.

(c) The traditional retailer only considers his profits maximization; meanwhile the manufacturer not only tries to maximize his own profits but also expands the whole market share as much as possible.

According to the above assumptions, the demand functions of the manufacturer and retailer are introduced as follows:

$$
\begin{aligned}
D_{r} & =\theta a-b_{1} p_{r}+k p_{m} \\
D_{m} & =(1-\theta) a-b_{2} p_{m}+k p_{r}
\end{aligned}
$$

where $a$ is the potential market size, $\theta \in(0,1)$ means the customer's loyalty to the traditional retailer channel, and $\theta a$ expresses the number of customer preferring the traditional retailer channel, while $(1-\theta) a$ represents the number of customer preferring the online channel of manufacturer. In addition, $b_{1}, b_{2}$ denote the price elasticity of $D_{r}, D_{m}, k$ means the cross-price sensitivity between two channels, and satisfies $b_{1}>k, b_{2}>k$.

Suppose that the price decision of the manufacturer and retailer occurs within the discrete-time period $(t=1,2,3, \ldots$, the price of the manufacturer and retailer in the $t$ period is $p_{i}(t)$, and the profit functions of the manufacturer and retailer are

$$
\begin{aligned}
\pi_{r}(t)= & \left(p_{r}(t)-w\right)\left(\theta a-b_{1} p_{r}(t)+k p_{m}(t)\right) \\
\pi_{m}= & (w-c)\left(\theta a-b_{1} p_{r}(t)+k p_{m}(t)\right) \\
& +\left(p_{m}(t)-c\right)\left((1-\theta) a-b_{2} p_{m}(t)+k p_{r}(t)\right) .
\end{aligned}
$$

Because manufacturer's sales revenue has the same change trends with its market share, we can use sale revenue substitute for market share $[10,15]$. 
Substituting (1) and (2) into (6) and (7), the marginal utility of retailer can be obtained by taking the first-order partial derivatives of utility function $\left(U_{r}\right)$ :

$$
\begin{aligned}
\frac{\partial U_{r}(t)}{\partial p_{r}(t)}= & \left(1+\lambda_{1}\right)\left(k p_{m}(t)+a \theta\right) \\
& +b_{1}\left[w-c \lambda_{1}+2 w \lambda_{1}-2 p_{r}(t)\left(1+\lambda_{1}\right)\right] .
\end{aligned}
$$

Similarly, we obtain the marginal utility of manufacturer as follows:

$$
\begin{aligned}
& \frac{\partial U_{m}(t)}{\partial p_{m}(t)}=a(1-\theta)+b_{2}\left(c \mu-2 p_{m}(t)\right) \\
& \quad+k\left[\left(1-\lambda_{2}\right) p_{r}(t)-c\left(\gamma \lambda_{2}+\mu\right)\right. \\
& \left.\quad+w\left(\lambda_{2}+\gamma \lambda_{2}+\mu\right)\right] .
\end{aligned}
$$

By solving $\partial U_{m}(t) / \partial p_{m}(t)=\partial U_{r}(t) / \partial p_{r}(t)=0$, we can get the best decisions of the manufacturer and retailer:

$$
\begin{aligned}
& p_{r}^{*}=\frac{\left\{a\left(k(\theta-1)-2 \theta b_{2}\right)\left(1+\lambda_{1}\right)+2 b_{1} b_{2}\left(w-c \lambda_{1}+2 w \lambda_{1}\right)+m_{0}\right\}}{\left(1+\lambda_{1}\right)\left(4 b_{1} b_{2}+k^{2}\left(\lambda_{2}-1\right)\right)} \\
& p_{m}^{*}=\frac{\left\{a\left(1+\lambda_{1}\right)\left(2 b_{1}(1-\theta)+k \theta\left(1-\lambda_{2}\right)\right)+2 b_{1} b_{2} c \mu\left(1+\lambda_{1}\right)+n_{0}\right\}}{\left(1+\lambda_{1}\right)\left(4 b_{1} b_{2}+k^{2}\left(\lambda_{2}-1\right)\right)},
\end{aligned}
$$

where $m_{0}=k\left(1+\lambda_{1}\right)\left(b_{2} c \mu+k\left(-c\left(\gamma \lambda_{2}+\mu\right)+w\left(\lambda_{2}+\gamma \lambda_{2}+\mu\right)\right)\right)$, $n_{0}=k w\left(1+\lambda_{1}+2\left(\gamma \lambda_{2}+\mu+\lambda_{1}\right)\right)+2 \lambda_{1}(1+k w-2 c)\left(\gamma \lambda_{2}+\right.$ $\mu)+\lambda_{1}\left(1-\lambda_{2}\right)$.

As a matter of fact, when players are making price decisions, they cannot get the complete information of the whole market and adjust their price strategy with bounded rationality. The manufacturer and retailer make their next period price decision based on the marginal utility of the current period. When the current marginal utility is positive, the price will be raised in the next period; otherwise, the price will be reduced in next period. The price adjustment process is as follows:

$$
\begin{aligned}
& p_{i}(t+1)=p_{i}(t)+\alpha_{j} p_{i}(t) \frac{\partial U_{i}(t)}{\partial p_{i}(t)} \\
&(j=1,2, i=r, m),
\end{aligned}
$$

where $\alpha_{j}>0$ represents the price adjustment speed and $\partial U_{i}(t) / \partial p_{i}(t)$ denote the marginal utility of the manufacturer or retailer.

Then, a discrete dynamic dual-channel Nash game model can be described:

$$
\begin{gathered}
p_{r}(t+1)=p_{r}(t)+\alpha_{1} p_{r}(t) \frac{\partial U_{r}(t)}{\partial p_{r}(t)} \\
p_{m}(t+1)=p_{m}(t)+\alpha_{2} p_{m}(t) \frac{\partial U_{m}(t)}{\partial p_{m}(t)} .
\end{gathered}
$$

\section{Model Stability Analysis}

We can get four equilibrium solutions by making $p_{r}(t+1)=$ $p_{r}(t), p_{m}(t+1)=p_{m}(t)$ :

$$
E_{1}=(0,0) \text {; }
$$

$$
\begin{aligned}
& E_{2}=\left(\frac{\left(1+\lambda_{1}\right) a \theta+b_{1}\left[w+\lambda_{1}(2 w-c)\right]}{2 b_{1}\left(1+\lambda_{1}\right)}, 0\right) ; \\
& E_{3}=(0, \\
& \left.\quad \frac{2 b_{2}\left[a(1-\theta)+b_{2} c \mu\right]+k\left[(w-c)\left(\gamma \lambda_{2}+\mu\right)+w \lambda_{2}\right]}{2 b_{2}}\right) ;
\end{aligned}
$$$$
E_{4}=\left(p_{r}^{*}, p_{m}^{*}\right)
$$

The Jacobian matrix of system (13) is given by

$$
J\left(p_{r}, p_{m}\right)=\left(\begin{array}{cc}
1+\alpha_{1} f_{1} & \alpha_{1} k\left(1+\lambda_{1}\right) p_{r} \\
\alpha_{2} k\left(1-\lambda_{2}\right) p_{m} & 1+\alpha_{2} f_{2}
\end{array}\right),
$$

where

$$
\begin{aligned}
f_{1} & =\left(1+\lambda_{1}\right)\left(k p_{m}+a \theta\right)+b_{1}\left[w-c \lambda_{1}+2 w \lambda_{1}\right. \\
& \left.-4 p_{r}\left(1+\lambda_{1}\right)\right] \\
f_{2} & =a(1-\theta)+b_{2}\left(c \mu-2 p_{m}\right)+k\left[\left(1-\lambda_{2}\right) p_{r}\right. \\
& \left.-c\left(\gamma \lambda_{2}+\mu\right)+w\left(\lambda_{2}+\gamma \lambda_{2}+\mu\right)\right] .
\end{aligned}
$$

The stability of equilibrium points is determined by the eigenvalues of Jacobian matrix evaluated at the corresponding equilibrium points. We substitute $E_{1}, E_{2}, E_{3}$, and $E_{4}$ into Jacobian matrix (15) and get the following proposition.

Proposition 1. $E_{1}, E_{2}$, and $E_{3}$ are boundary equilibrium points and unstable points; $E_{4}$ is the only Nash equilibrium solution. 
Proof. For equilibrium point $E_{1}$, the Jacobian matrix of system (13) is equal to

$$
J\left(E_{1}\right)=\left(\begin{array}{cc}
1+\alpha_{1}\left[\left(1+\lambda_{1}\right) a \theta+b_{1}\left(w-c \lambda_{1}+2 w \lambda_{1}\right)\right] & 0 \\
0 & 1+\alpha_{2}\left[a(1-\theta)+b_{2} c \mu+k\left((w-c)\left(\gamma \lambda_{2}+\mu\right)+w \lambda_{2}\right)\right]
\end{array}\right)
$$

which gives two eigenvalues:

$$
\begin{aligned}
r_{1} & =1+\alpha_{1}\left[\left(1+\lambda_{1}\right) a \theta+b_{1}\left(w-c \lambda_{1}+2 w \lambda_{1}\right)\right], \\
r_{2} & =1+\alpha_{2}\left[a(1-\theta)+b_{2} c \mu\right. \\
& \left.+k\left((w-c)\left(\gamma \lambda_{2}+\mu\right)+w \lambda_{2}\right)\right] .
\end{aligned}
$$

Obviously, $r_{1}>1, r_{2}>1$ imply that $E_{1}$ is unstable.

For $E_{2}$, we calculate the eigenvalues of its Jacobian matrix:

$$
\begin{aligned}
r_{1}= & 1-\alpha_{1} b_{1}\left(w-c \lambda_{1}+2 w \lambda_{1}\right)-\alpha_{1} a \theta\left(1+\lambda_{1}\right), \\
r_{2} & \\
= & 1+\alpha_{2}\left[(w-c)\left(\gamma \lambda_{2}+\mu\right)+w \lambda_{2}+b_{2} c \mu\right] \\
& +\frac{a k \theta \alpha_{2}\left(1+\lambda_{1}\right)\left(1-\lambda_{2}\right)}{2 b_{1}} \\
& +\frac{k \alpha_{2}\left(w+2 w \lambda_{1}-c \lambda_{1}\right)\left(1-\lambda_{2}\right)+2 a \alpha_{2}(1-\theta)}{2} .
\end{aligned}
$$

We can see that $r_{1}<1, r_{2}>1$ which indicates that $E_{2}$ is an unstable point. More precisely, $E_{2}$ is a saddle point for $\left|r_{1}\right|<1$. We can prove $E_{3}$ is also an unstable point in the same way; $E_{4}$ is the unique Nash equilibrium solution of the system.

Next, we only consider the stability of the Nash equilibrium point, the corresponding characteristic polynomial of system (13) can be written as follows:

$$
f(\lambda)=\lambda^{2}+A \lambda+B
$$

where

$$
\begin{aligned}
A= & 2+\alpha_{1} f_{1}+\alpha_{2} f_{2} \\
B= & \left(1+\alpha_{1} f_{1}\right)\left(1+\alpha_{2} f_{2}\right) \\
& -\left[\alpha_{1} k\left(1+\lambda_{1}\right) p_{r}\right]\left[\alpha_{2} k\left(1-\lambda_{2}\right) p_{m}\right] .
\end{aligned}
$$

$A$ and $B$ represent the trace and determinant of the Jacobian matrix $J\left(P_{r}^{*}, P_{m}^{*}\right)$, respectively.

The necessary and sufficient condition of asymptotic stability is that all the eigenvalues are inside the unit circle in complex plane, so the stability of system should satisfy the Jury's conditions known as

$$
\begin{gathered}
F(1)=1-A+B>0 \\
F(-1)=1+A+B>0 \\
F(0)=1-|B|>0 .
\end{gathered}
$$

\section{Numerical Simulations}

In this section, numerical simulations are used to show the dynamic behaviors and features of system (13). We choose some values for parameters based on actual competition; values for parameters are as follows: $a=100, \theta=0.4, b_{1}=0.3$, $b_{2}=0.4, k=0.2, c=100$, and $w=122.5$.

4.1. The Influence of $\mu, \lambda_{1}$, and $\lambda_{2}$ on the Stability Region of Nash Equilibrium. Only if the initial values are in the stability region of Nash equilibrium, the prices of players will be fixed at Nash equilibrium point after a series of iterations.

Figure 1(a) shows the stability regions of the Nash equilibrium point with different values of $\mu$ when $\lambda_{1}$ and $\lambda_{2}$ are fixed at 0.2 . We can see that the stability region is the biggest with $\mu=0.2$, when $\mu=0.6,0.9$; the stable region becomes small gradually. Figure $1(\mathrm{~b})$ shows the stability regions of the Nash equilibrium point with different values of $\lambda_{1}$ when $\mu=$ $0.6, \lambda_{2}=0.2$; the stability region becomes smaller with $\lambda_{1}$ increasing and the scope of $\alpha_{1}$ is decreasing at the same time; the system stability is more sensitive to $\alpha_{1}$ than $\alpha_{2}$; in this case, the retailer should be more cautious than manufacturer in adjusting the price strategy. Similarly, Figure 1(c) shows that the stability region of Nash equilibrium is expanded with $\lambda_{2}$ increasing.

The parameter basin is a kind of two-dimensional bifurcation diagram; 2D period diagram of system (13) in the $\left(\alpha_{1}, \alpha_{2}\right)$ plane is displayed in Figure 2, which shows the route of system (13) to chaos. Different colors represent different periods: period-1 (red), period-2 (blue), period3 (light blue), period-4 (yellow), period-5 (pink), period7 (orange), period-8 (purple), chaos (white), and divergence (coral). By comparing the size of the stability region (red region) in Figures 2(a), 2(b), and 2(c), we can find that the high level fairness concern of retailer will shrink the stability region of Nash equilibrium, while manufacturer's fairness concern can extend the stability region of it.

From the diagrams with different parameter values in Figure 2, some conclusions can be obtained: (1) the manufacturer sets market share as one of the business objectives that can extend the stability region of the Nash equilibrium. (2) The retailer considering fairness concern is disadvantageous to keeping the Nash equilibrium point in stability region; it indicates that a high level fair caring retailer will push the system to fall into chaos earlier. (3) A fair caring manufacturer is beneficial to expanding the Nash equilibrium point's stability region. 


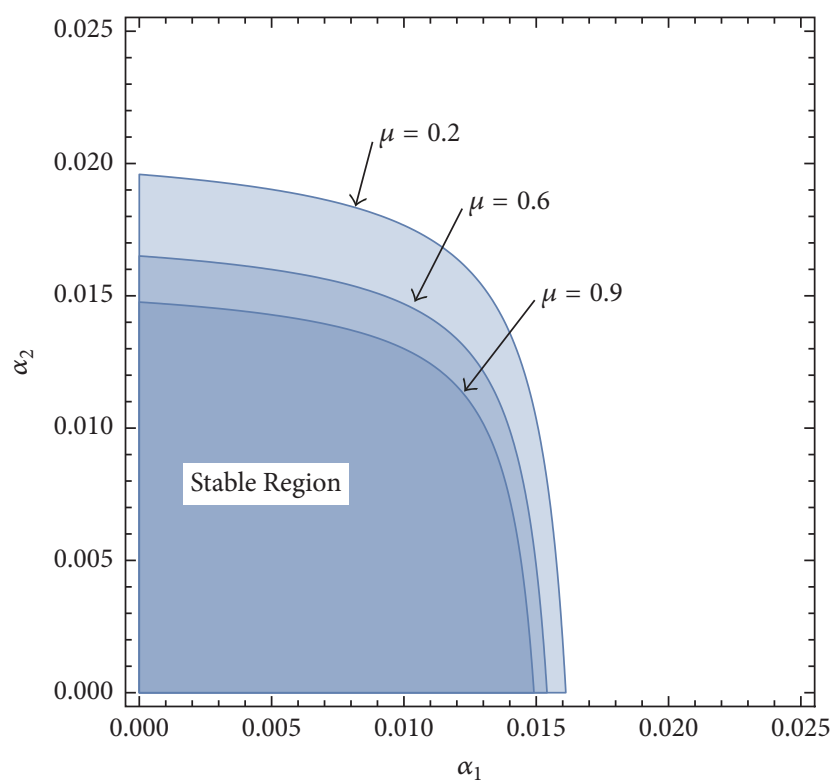

(a) The stability regions in the phase plane of $\left(\alpha_{1}, \alpha_{2}\right)$ with different values of $\mu$

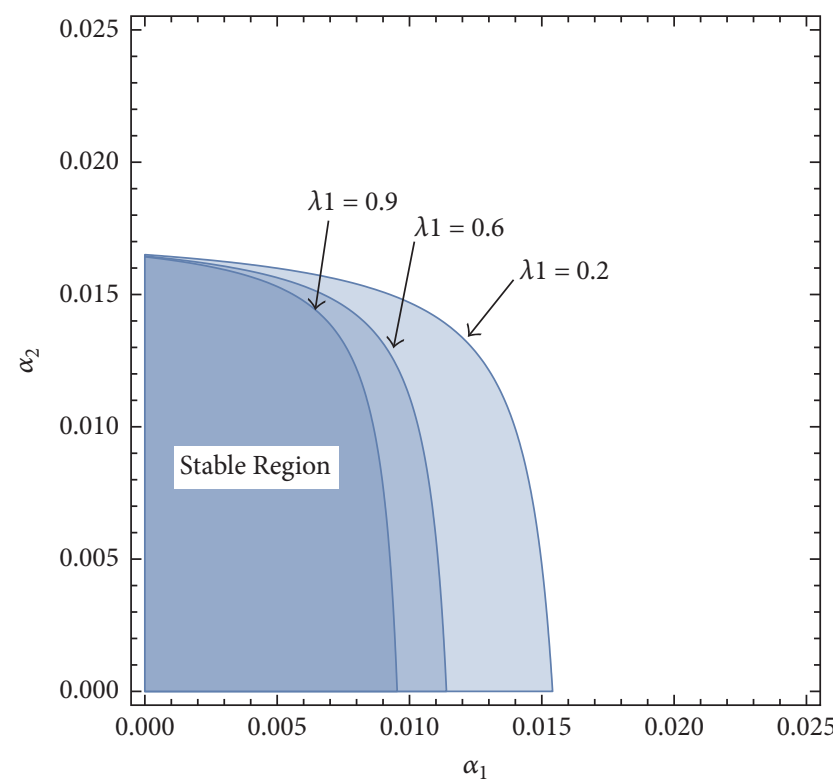

(b) The stability regions in the phase plane of $\left(\alpha_{1}, \alpha_{2}\right)$ with different values of $\lambda_{1}$

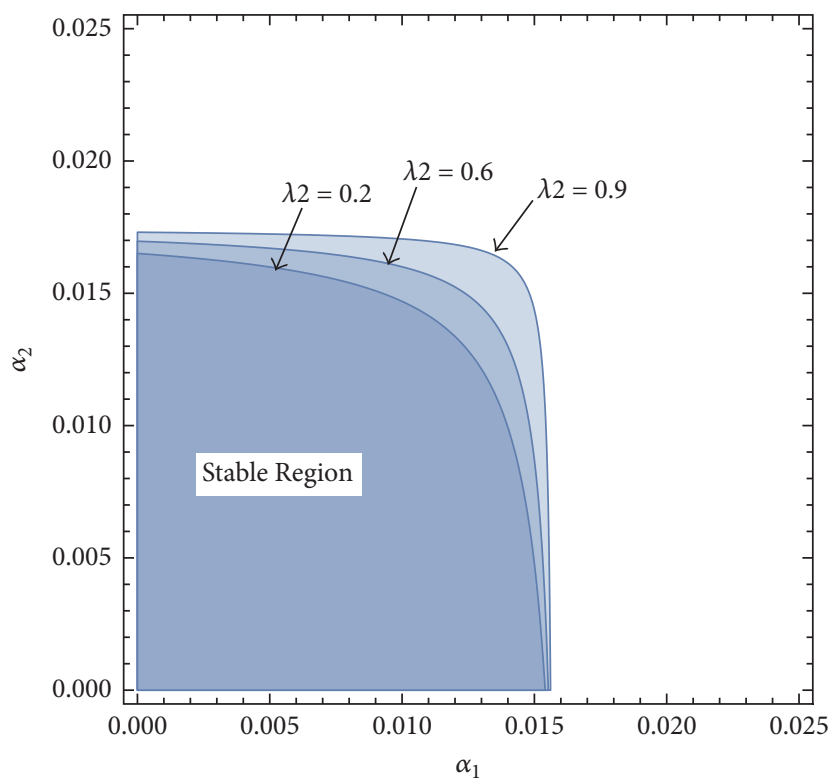

(c) The stability regions in the phase plane of $\left(\alpha_{1}, \alpha_{2}\right)$ with different values of $\lambda_{2}$

Figure 1
4.2. The Influence of the Price Adjustment Speed on the System Behavior. First of all, Figure 3(a) is bifurcation diagram of the dynamic system (13) when $\mu=0.6, \lambda_{1}=0.2$, and $\lambda_{2}=0.2$. When $\alpha_{1}$ is fixed, with $\alpha_{2}$ increasing from 0 to 0.025 , the Nash equilibrium of system (13) loses its stability through the flip bifurcation and a stable period-2 cycle appears after the bifurcation at $\alpha_{2}=0.016$; then period-doubling bifurcation repeats and enters into chaos finally. The corresponding Largest Lyapunov exponent (LLE) is shown in Figure 3(b), with $\alpha_{2}$ varying from 0 to 0.025 , the Lyapunov exponent is negative at the beginning; with the $\alpha_{2}$ increases, most of the
LLEs are bigger than 0, which indicates the appearance of chaos.

Figure 4 shows the chaotic attractors of system (13) when $\alpha_{1}=0.005,0.012$, and $\alpha_{2}=0.022$, which is one of the most important characteristics of the complex system. Figure 5(a) shows a stable period-2 cycle of price when $\alpha_{1}=0.005$, $\alpha_{2}=0.02$; the price fluctuates rhythmically and the Nash equilibrium loses its stability. In Figure 5(b), the prices of the system change irregularly and get bogged down chaotically with $\alpha_{2}=0.022$. Figure 6 shows the sensitivity dependence to initial conditions of the system when $\alpha_{1}=0.005, \alpha_{2}=0.022$; 


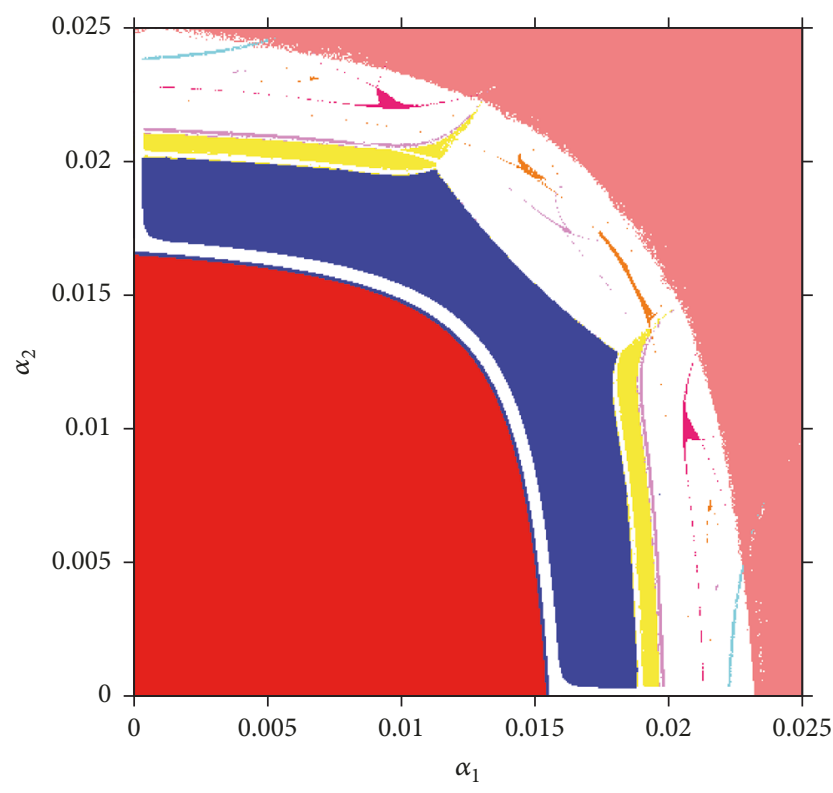

(a) $\lambda_{1}=\lambda_{1}=0.2$

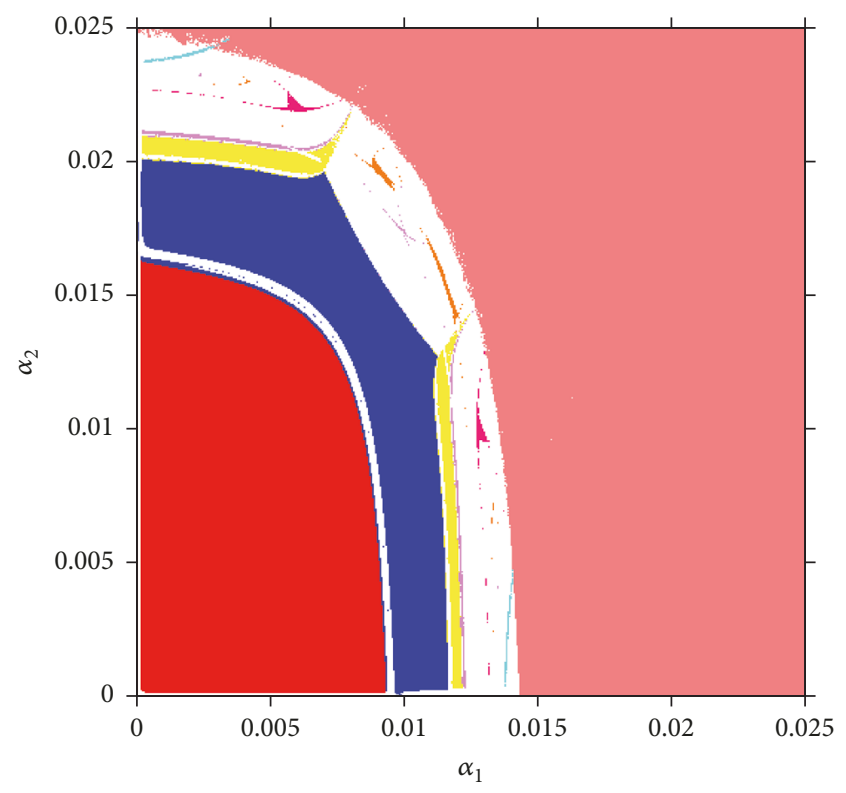

(b) $\lambda_{1}=0.9, \lambda_{2}=0.2$

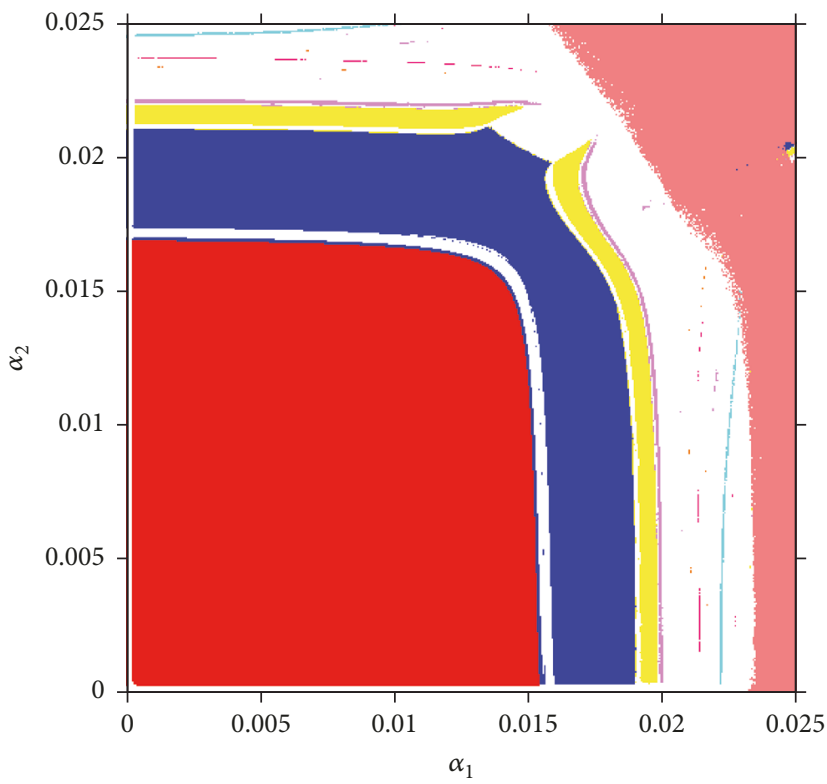

(c) $\lambda_{1}=0.2 \lambda_{2}=0.9$

FIGURE 2: 2D parameter bifurcation in the $\left(\alpha_{1}, \alpha_{2}\right)$ plane (red (stable), blue (2-period), light blue (3-period), yellow (4-period), pink (5-period), orange (7-period), purple (8-period), white (chaos), and coral (divergence)).

the system falls into chaos, the initial price changes even a little bit, and the orbit of price will be dramatically different with initial price. We do not have to describe the dynamic behaviors of system (13) when $\alpha_{1}$ is changing, which is the same as the change of $\alpha_{2}$.

4.3. Performance Measures. Profit is one of the most important indexes to measure the performance of the system and is used frequently in a large number of business researches. In this section, we mainly investigate the impact of $\lambda_{i}, \alpha_{i}$ on players' profits and average profit over time.
4.3.1. The Influence of $\lambda_{i}, \alpha_{i}$ on the Profit $\pi_{r}, \pi_{m}$. Table 1 shows that as the retailer's level of fairness concern is increased, the price of the manufacturer and the retailer can also be raised up. On the contrary, as we can see from Table 2, the high level fairness concern of manufacturer will reduce profit for the whole supply chain. Moreover, $\pi_{T}=\pi_{r}+\pi_{m}$, which is profits gains of the supply chain. $\pi_{T}$ change a little bit with $\lambda_{1}$ increases in Table 1. In Table 2, with $\lambda_{2}$ raised, $\pi_{T}$ is decreased sharply.

Figure 7 shows the fluctuation of profits with the changing of time when the system is in chaotic state. In Figure 8(a), 


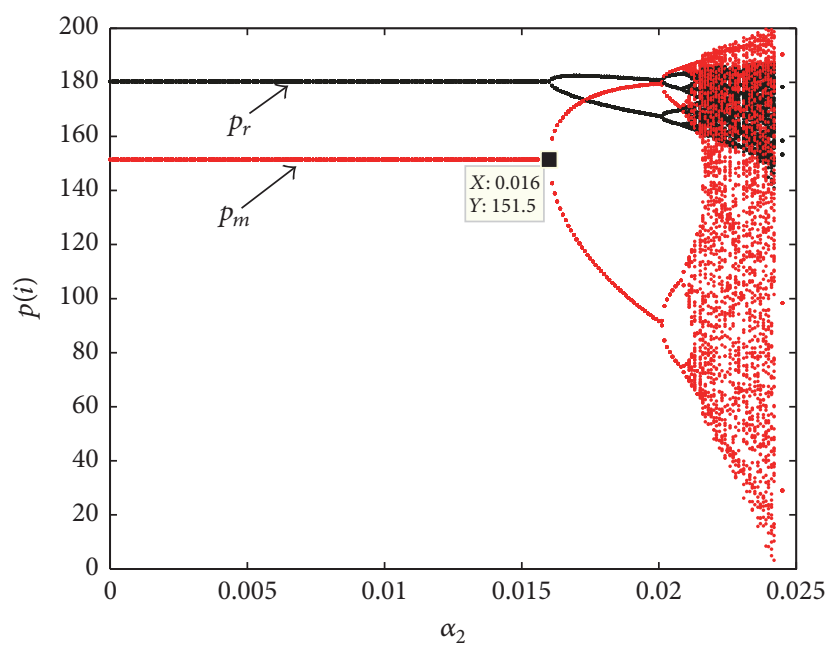

(a) Bifurcation diagram of the dynamic system (15) for $\alpha_{2}$, when $\alpha_{1}=0.005$

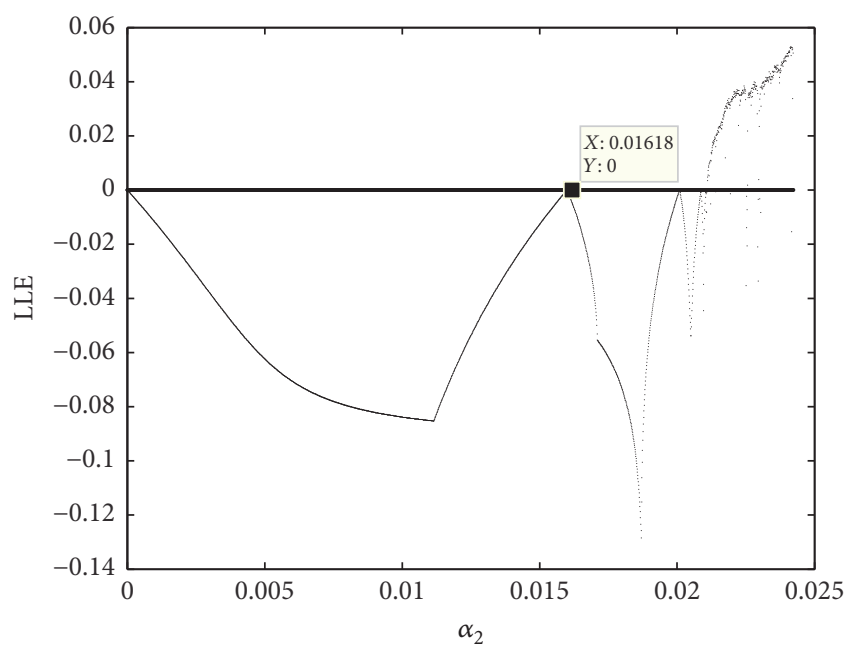

(b) The corresponding Largest Lyapunov exponent for $\alpha_{2}$ varying from 0 to 0.025

FIgURE 3: The bifurcation diagram and LLE with respect to $\alpha_{2}$.

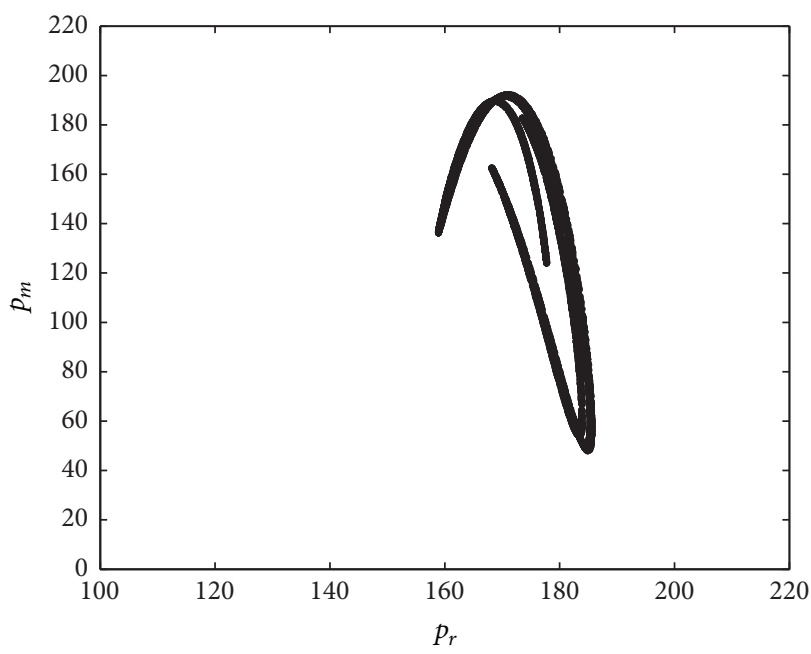

(a) $\alpha_{1}=0.005$

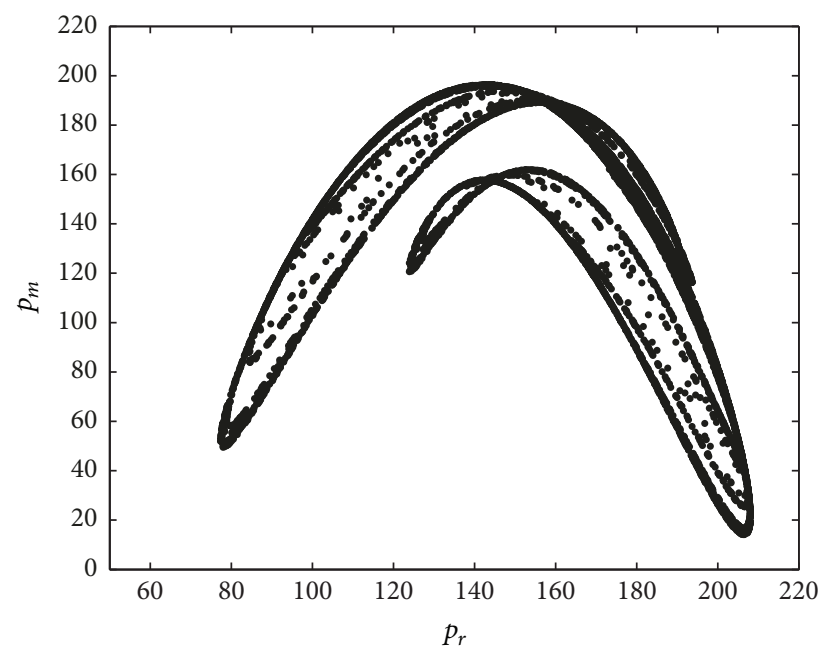

(b) $\alpha_{1}=0.012$

FIGURE 4: Chaotic attractors of the system when $\alpha_{2}=0.022$.

TABLE 1: The prices and profits with different level fairness concerns of retailer when $\mu=0.6, \lambda_{2}=0.2$.

\begin{tabular}{lcccc}
\hline & $\lambda_{1}=0$ & $\lambda_{1}=0.2$ & $\lambda_{1}=0.6$ & $\lambda_{1}=0.9$ \\
\hline$P_{r}$ & 178,27 & 180.28 & 182.79 & 183.98 \\
$P_{m}$ & 151.05 & 151.46 & 151.96 & 152.20 \\
$\pi_{r}$ & 933.02 & 936.45 & 937.79 & 937.28 \\
$\pi_{m}$ & 2175.16 & 2190.00 & 2208.75 & 2217.75 \\
$\pi_{T}$ & 3108.18 & 3126.45 & 3146.54 & 3155.03 \\
\hline
\end{tabular}

the average profit with respect to $\alpha_{1}$ is demonstrated; when $\alpha_{1}<0.0151$, the average profits of the manufacturer and the retailer are fixed at a certain value. The average profits of both sides will decrease with $\alpha_{1}$ increasing when $\alpha_{1}>0.0151$, especially in retailer's profit. Similarly, when
TABLE 2: The prices and profits with different level fairness concerns of manufacturer when $\mu=0.6, \lambda_{1}=0.2$.

\begin{tabular}{lcccc}
\hline & $\lambda_{2}=0$ & $\lambda_{2}=0.2$ & $\lambda_{2}=0.6$ & $\lambda_{2}=0.9$ \\
\hline$P_{r}$ & 181.00 & 180.28 & 178.91 & 177.94 \\
$P_{m}$ & 153.63 & 151.46 & 147.34 & 144.44 \\
$\pi_{r}$ & 960.86 & 936.45 & 891.01 & 859.61 \\
$\pi_{m}$ & 2233.03 & 2190.00 & 2099.68 & 2029.14 \\
$\pi_{T}$ & 3193.89 & 3126.45 & 2990.69 & 2888.75 \\
\hline
\end{tabular}

$\alpha_{2}>0.0162$ in Figure 8(b), the average profit of both sides will be declined with $\alpha_{2}$ raising. A faster adjustment speed of price in manufacturer or retailer is disadvantageous for the system to keeping stability and achieving the profit maximization. 


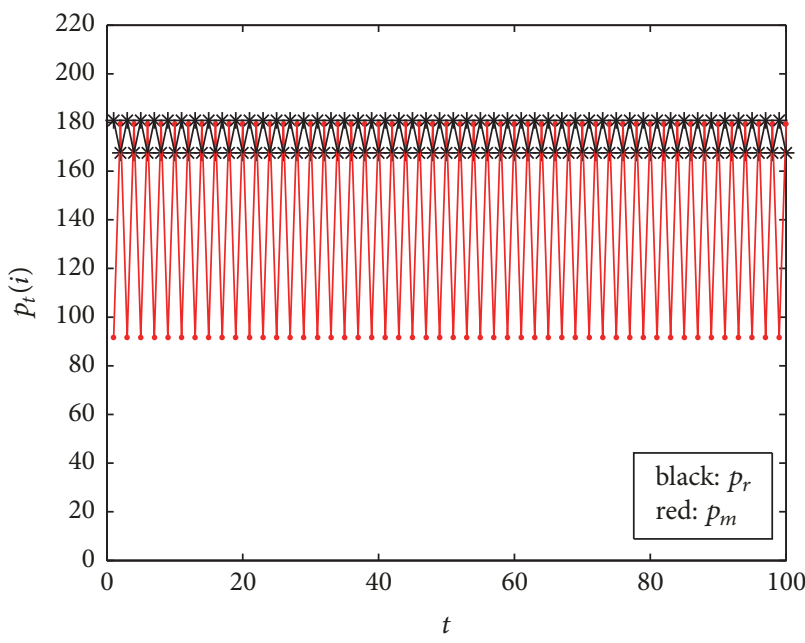

(a) $\alpha_{2}=0.02$

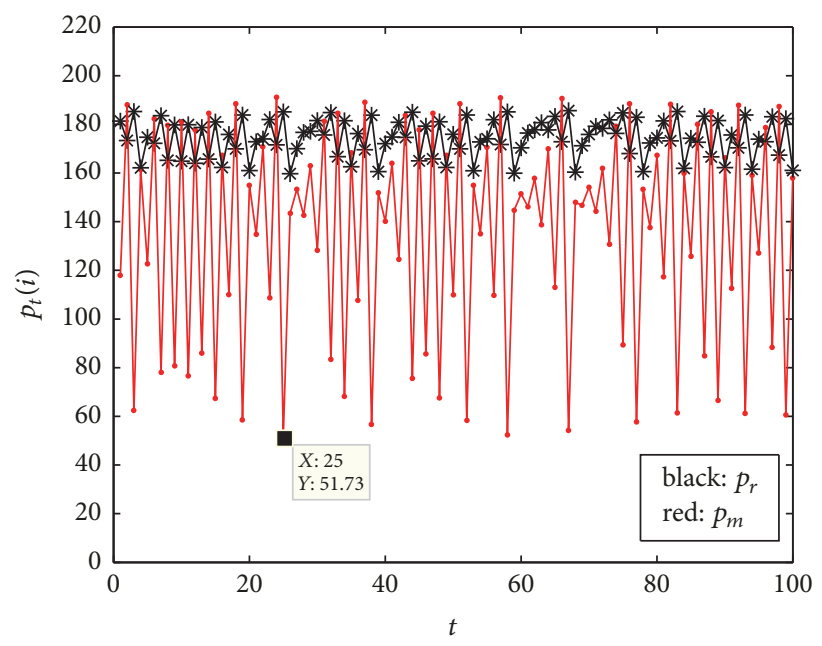

(b) $\alpha_{2}=0.022$

Figure 5: The prices wave plot of system (15) with change of time when $\alpha_{1}=0.005$.

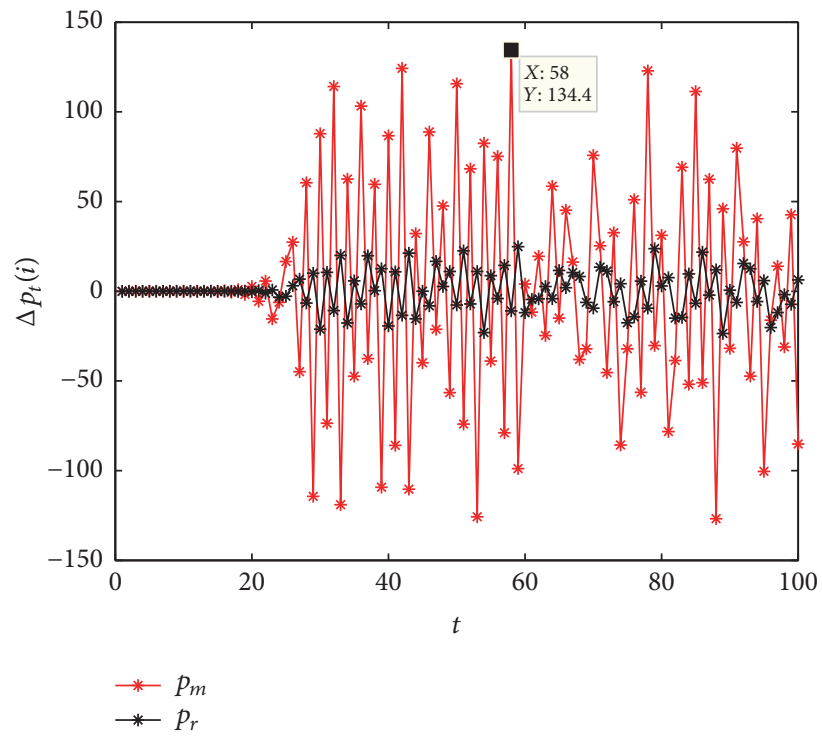

FIGURE 6: Sensitivity dependence to initial conditions with $\left(p_{r}, p_{m}\right)$ $=(180.277,151.455)$ and $(180.277,151.4551)$.

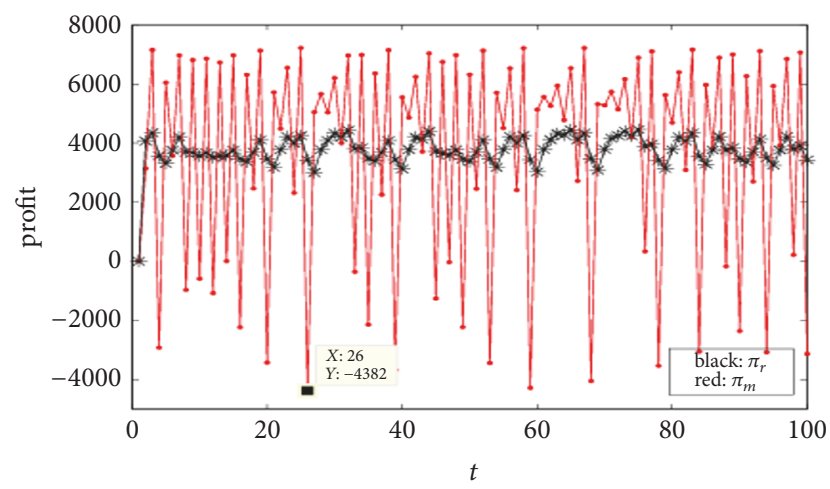

FIGURE 7: The profits diagram with changing of time when $\alpha_{1}=$ $0.005, \alpha_{2}=0.022$.
Once the market loses stability and goes into chaos, the market becomes unpredictable and leads to the interest loss of participators, so it is essential for manufacturer and retailer to keep the adjustment parameters in a certain range for avoiding the system becoming chaotic.

4.3.2. The Influence of $\lambda_{i}$ and $\alpha_{i}$ on the $\pi_{r}, \pi_{m}$. In this section, in order to show changing trend of players' profits clearly, we emphasis on caring about the influence of $\lambda_{i}$ and $\alpha_{i}$ on $\pi_{r}, \pi_{m}$. The change of $\pi_{r}, \pi_{m}$ is shown by 3D meshes in the Figure 9. Figure 9 shows that the $\pi_{r}, \pi_{m}$ will make a sharp reduction finally with increasing of $\lambda_{i}, \alpha_{i} . \pi_{r}$ can remain stable when $\lambda_{1} ; \alpha_{2}$ are in stability region (red region in Figure 2). As $\alpha_{2}$ exceeds 0.016 , the profit $\pi_{r}$ becomes unstable and drastic variation occurs (white region on Figure 2); meanwhile, most of the profits are lower than before. The changes of $\pi_{m}$ with respect to $\lambda_{2}$ and $\alpha_{2}$ are shown in Figure 9(b) when $\alpha_{2}$ is fixed at 0.016 . With the $\lambda_{2}$ increasing, the $\pi_{m}$ will fall into instability region and even enormous loss occurs. Otherwise, we can analyze other situations about change of $\pi_{r}, \pi_{m}$ with the change of $\lambda_{1}, \alpha_{1}$ and $\lambda_{2}, \alpha_{1}$, shown in Figure 9(c), and $\lambda_{2}$, $\alpha_{1}$, shown in Figure 9(d). According to the analysis above, the manufacturer and retailer should pay attention to the range of value in $\lambda_{i}, \alpha_{i}$ to avoid interest loss and achieve their own business objectives.

\section{Chaos Control}

As shown above, once chaos occurs in a complex and dynamic supply chain, the manufacturer and retailer will find that it is not easy to maintain the market at equilibrium state, because there are so many factors having significant influence on the equilibrium state, such as the price adjustment speed of competitors, the customer's behavior, and the ability to collect information. When the system loses stability, it will become disorderly and unpredictable. In order to achieve business objectives, the efficient measures of chaos control 


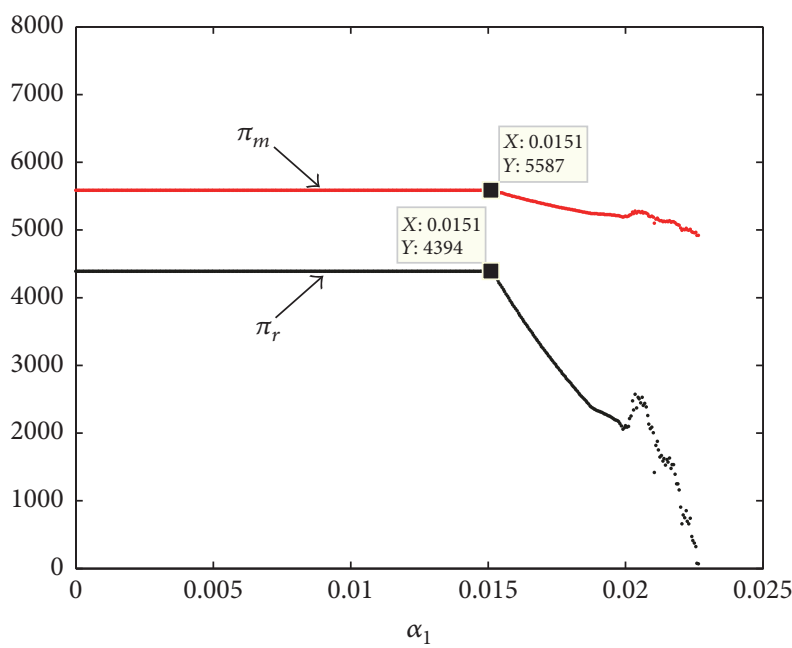

(a) The changes of average profit with respect to $\alpha_{1}$ when $\alpha_{2}=0.005$

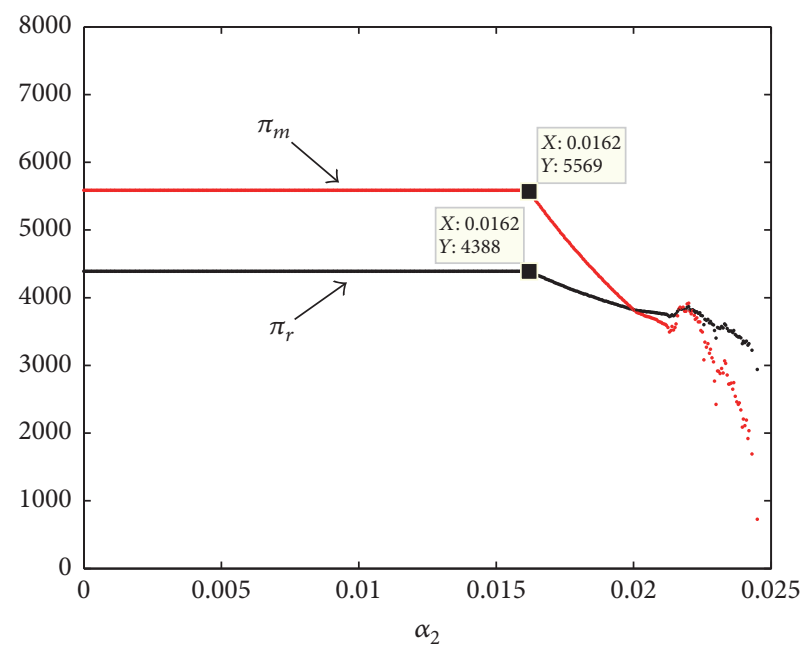

(b) The changes of average profit with respect to $\alpha_{2}$ when $\alpha_{1}=0.005$

FIGURE 8: The change of average profit with respect to $\alpha_{1}$ and $\alpha_{2}$.

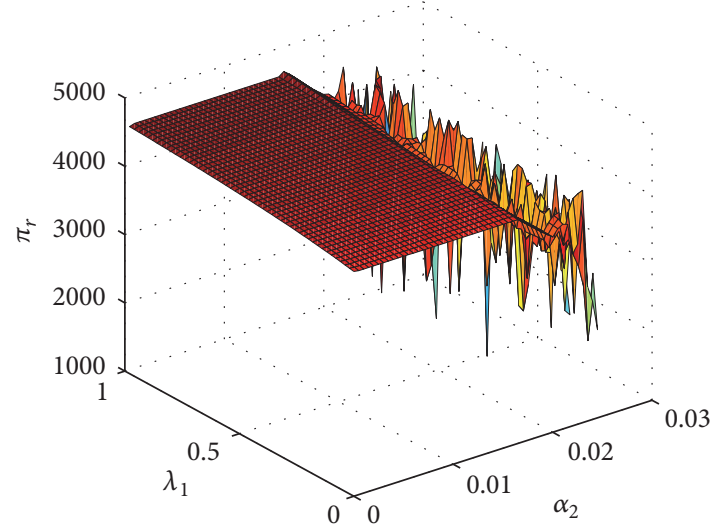

(a) $\lambda_{1}, \alpha_{2}$

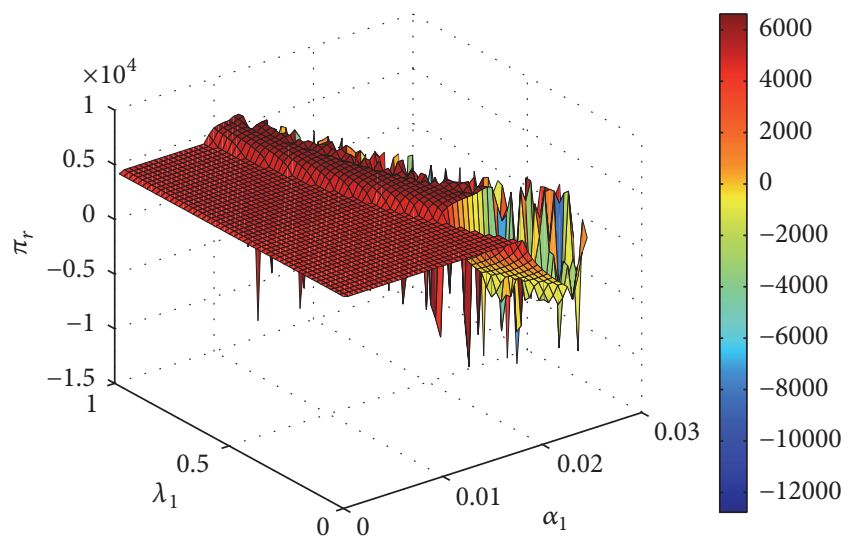

(c) $\lambda_{1}, \alpha_{1}$

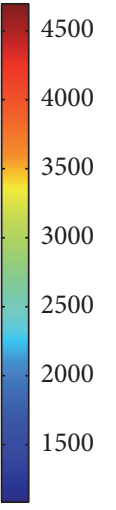

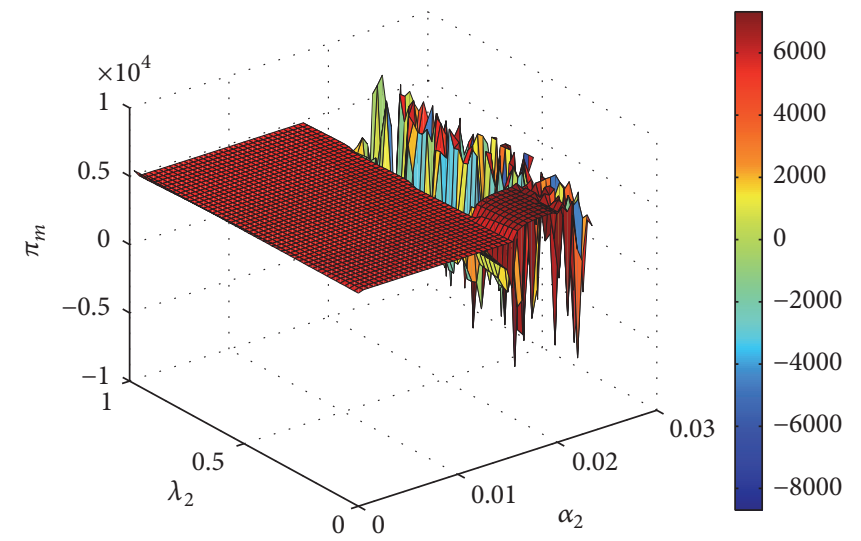

(b) $\lambda_{2}, \alpha_{2}$

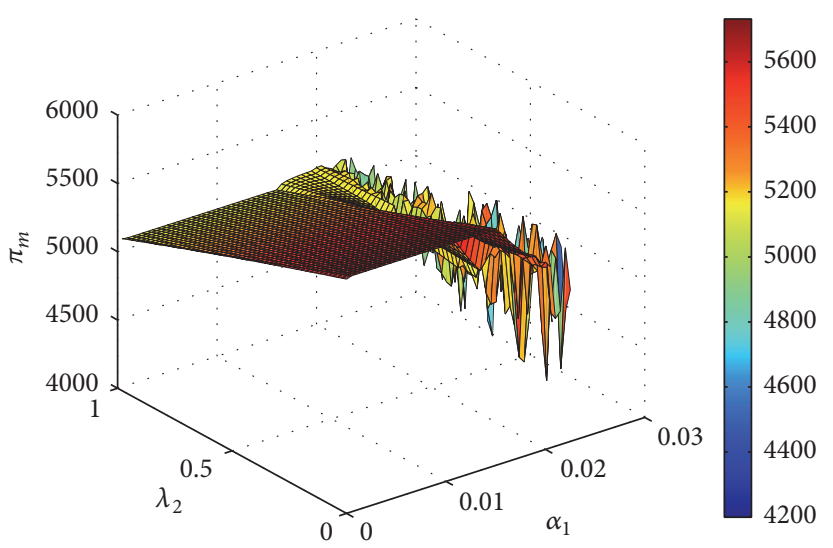

(d) $\lambda_{2}, \alpha_{1}$

Figure 9: The change of profit of the system with respect to $\lambda_{i}, \alpha_{i}$.

should be taken to make the system return to a stable state, for example, adaptive adjustment mechanism [31], the variable feedback control method $[2,35]$. In this paper, we use adaptive adjustment mechanism to establish a control model for system (13). Assume the original system (13) is described by $p_{i}(t+1)=f_{i}\left(p_{m}(t), p_{r}(t)\right)$. Then the controlled system can be written as follows:

$$
\begin{aligned}
& p_{r}(t+1)=(1-v) f_{1}\left(p_{m}(t), p_{r}(t)\right)+v p_{r}(t) \\
& p_{m}(t+1)=(1-v) f_{2}\left(p_{m}(t), p_{r}(t)\right)+v p_{m}(t),
\end{aligned}
$$




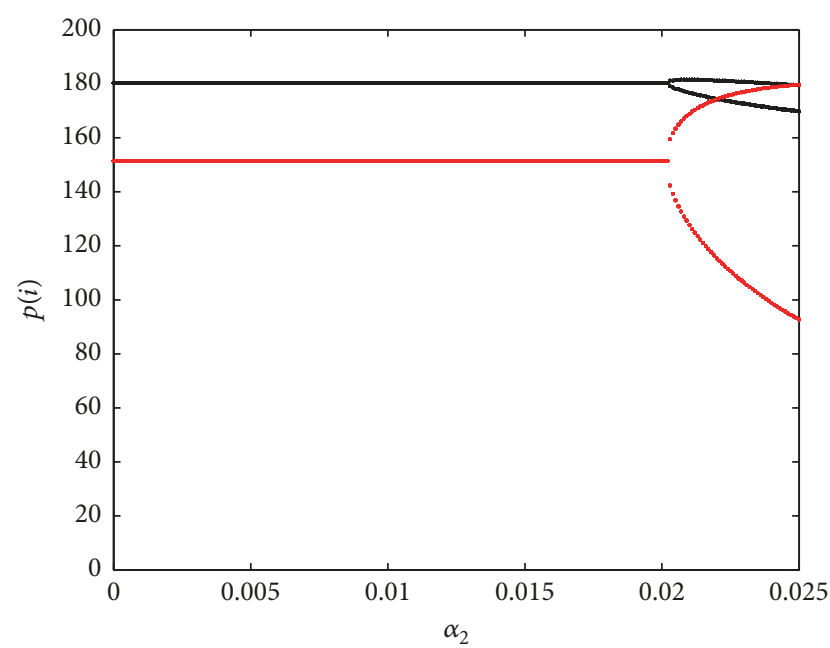

(a) $v=0.2$

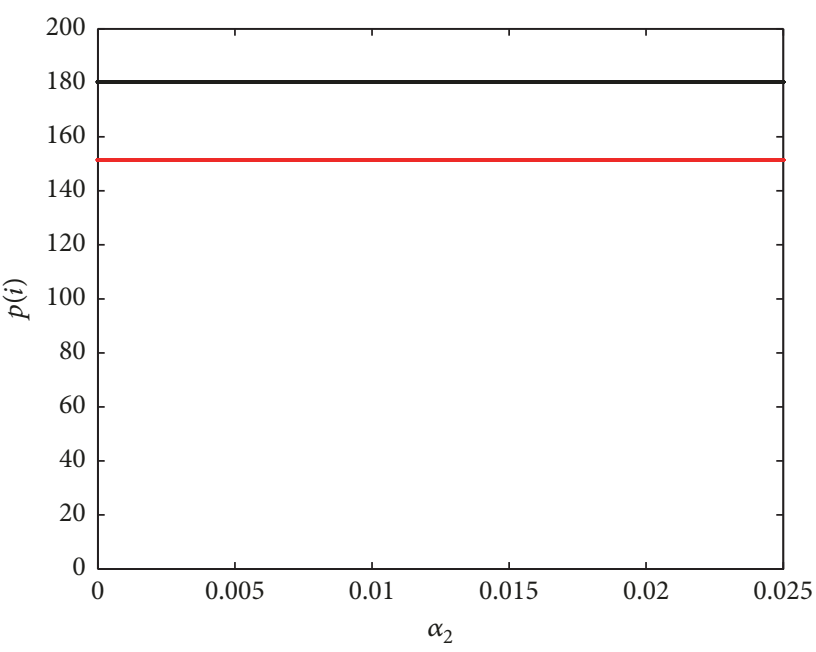

(b) $v=0.5$

FIGURE 10: Bifurcation diagram with respect to $\alpha_{2}$, when $\alpha_{1}=0.005$.

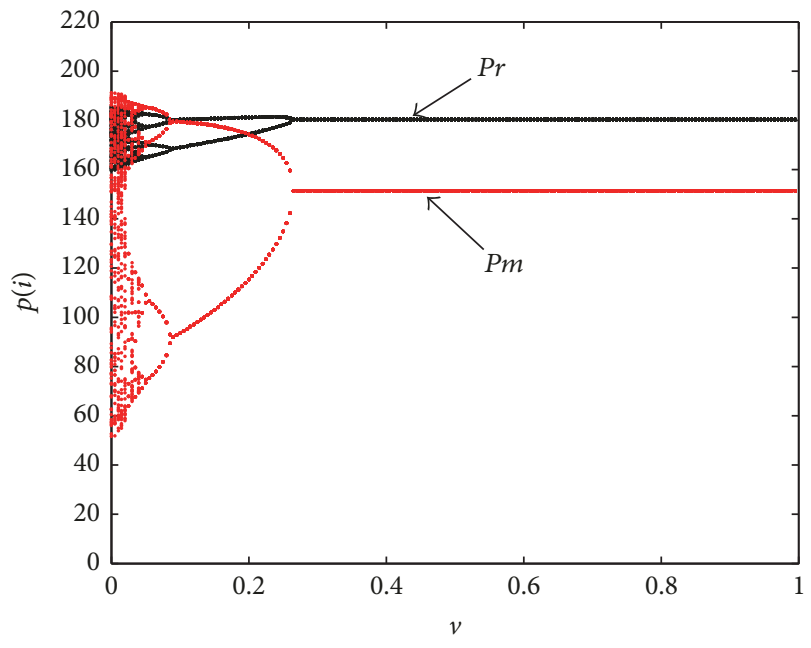

(a)

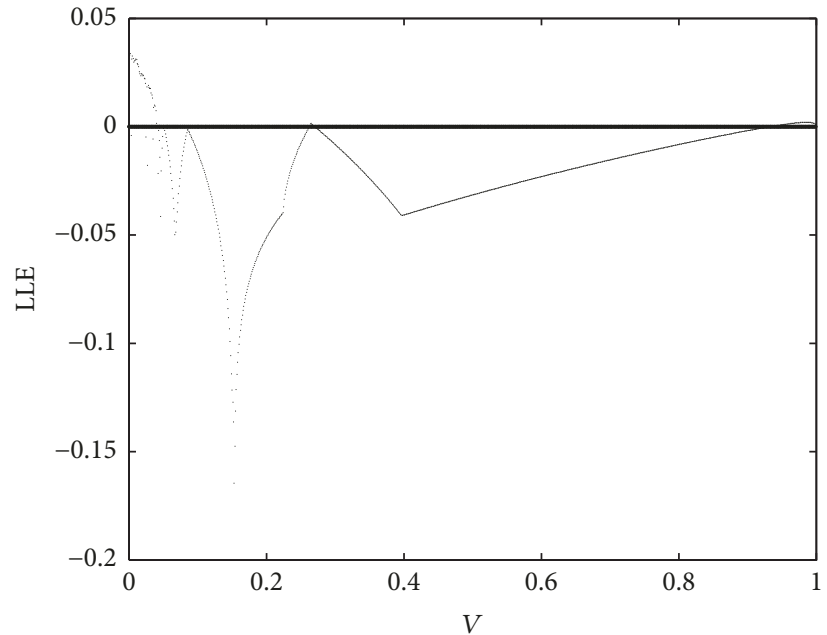

(b)

FIGURE 11: Bifurcation diagram and Lyapunov exponent of system (11) with $v \in(0,1), \alpha_{1}=0.005$, and $\alpha_{2}=0.022$.

where $v$ is the adjustment parameter, which can be regarded as the regulation of government in controlling the price adjustment speed or learning ability and adaptability of participants in the market. When $v=0$, the controlled system (23) becomes the original system (13). Figure 10 shows that the chaos can be delayed or eliminated with a proper value of $v$. When $v=0.2$, the price is stable in period-doubling bifurcation state; when $v=0.5$, the system will always maintain stability state even though the adjustment speed of price is big enough. Figure 9(a) shows the bifurcation diagram of price against the adaptive parameter $v$. Figure 9(b) shows the corresponding Largest Lyapunov exponents change from positive at start to negative at the end, which indicates that system (23) returns to a stable state. Figure 11 is the bifurcation diagram and LEE of the controlled system (11) with the change of $v$. So we can see that the controlled system (11) can return to stable state from chaos state with appropriate parameter values.

\section{Conclusions}

In this paper, we studied a dual-channel supply chain model, which includes a dual-channel manufacturer who considers fairness concern and different business objectives and a fair caring retailer. The dynamic behaviors of the players and complexity characteristic of the system are analyzed by simulation, like bifurcation, 2D period bifurcation, chaotic attractors, sensitivity dependence to initial conditions, and so on. The change of profits is demonstrated by $3 \mathrm{D}$ meshes and average profit is also analyzed. The adaptive adjustment mechanism is used to control chaos. The results show that the excessive price adjustment speed will lead to the system 
losing its stability as well as leading to profit loss. The fair caring behavior of the retailer is disadvantageous to keeping stability for the system, which will push the system to fall into chaos earlier. The manufacturer considering fairness concern and setting market share as one of its business objectives are beneficial to expanding the stability region of Nash equilibrium.

The study of complexity of dynamic price model based on fairness concerns and different business objectives has theoretical and practical significance. The supply chain managers can do the correct and efficient decision. Nonetheless, we do not take some factors into account, for example, the risk sensitivity of decision-makers; if so the model will have more reality than before. Other channel structures between the manufacturer and retailer should be taken into account. We believe the ideas in this paper will lay the motivational ground for future research in these directions.

\section{Conflicts of Interest}

The authors declare that there are no conflicts of interest regarding the publication of this paper.

\section{Acknowledgments}

The research was supported by Henan Province Soft Science Research Plan Project (no. 182400410054).

\section{References}

[1] K. Takahashi, T. Aoi, D. Hirotani, and K. Morikawa, "Inventory control in a two-echelon dual-channel supply chain with setup of production and delivery," International Journal of Production Economics, vol. 133, no. 1, pp. 403-415, 2011.

[2] J. Ma and L. Xie, "The comparison and complex analysis on dual-channel supply chain under different channel power structures and uncertain demand," Nonlinear Dynamics, vol. 83, no. 3, pp. 1379-1393, 2016.

[3] Q. Lu and N. Liu, "Effects of e-commerce channel entry in a two-echelon supply chain: a comparative analysis of singleand dual-channel distribution systems," International Journal of Production Economics, vol. 165, pp. 100-111, 2015.

[4] G. S. Cai, "Channel selection and coordination in dual-channel supply chains," Journal of Retailing, vol. 86, no. 1, pp. 22-36, 2010.

[5] X. Chen and X. Wang, "Free or bundled: channel selection decisions under different power structures," Omega, vol. 53, pp. 11-20, 2015 .

[6] Z. Liu and Q. Xu, "Collaborative optimal pricing model of dualchannel supply Chain," Open Cybernetics and Systemics Journal, vol. 9, pp. 775-785, 2015.

[7] J. Gao, X. Wang, Q. Yang, and Q. Zhong, "Pricing decisions of a dual-channel closed-loop supply chain under uncertain demand of indirect channel," Mathematical Problems in Engineering, Article ID 6053510, Art. ID 6053510, 13 pages, 2016.

[8] W. Huang and J. M. Swaminathan, "Introduction of a second channel: implications for pricing and profits," European Journal of Operational Research, vol. 194, no. 2, pp. 258-279, 2009.
[9] G. Xu, B. Dan, X. Zhang, and C. Liu, "Coordinating a dualchannel supply chain with risk-averse under a two-way revenue sharing contract," International Journal of Production Economics, vol. 147, pp. 171-179, 2014.

[10] D. E. Bell, R. L. Keeney, and J. D. C. Little, "A Market Share Theorem," Journal of Marketing Research, vol. 12, no. 2, pp. 136141, 1975.

[11] G. S. Carpenter, L. G. Cooper, D. M. Hanssens, and D. F. Midgley, "Modeling Asymmetric Competition," Marketing Science, vol. 7, no. 4, pp. 393-412, 1988.

[12] D. M. Szymanski, S. G. Bharadwaj, and P. R. Varadarajan, "An Analysis of the Market Share-Profitability Relationship," Journal of Marketing, vol. 57, no. 3, pp. 1-18, 1993.

[13] B. K. Dutta and W. R. King, "Competitive scenario modeling system," Management Science, vol. 26, no. 3, pp. 261-273, 1980.

[14] T. Li and J. Ma, "Complexity analysis of dual-channel game model with different managers' business objectives," Communications in Nonlinear Science and Numerical Simulation, vol. 20, no. 1, pp. 199-208, 2015.

[15] T. H. Cui, J. S. Raju, and Z. J. Zhang, "Fairness and channel coordination," Management Science, vol. 53, no. 8, pp. 1303-1314, 2007.

[16] V. Pavlov and E. Katok, "Fairness and Coordination Failures in Supply Chain Contracts," SSRN Electronic Journal.

[17] E. Katok, T. Olsen, and V. Pavlov, "Wholesale pricing under mild and privately known concerns for fairness," Production \& Operations Management, vol. 23, no. 2, pp. 285-302, 2014.

[18] S.-F. Du, C. Du, and L. Liang, "Supply chain coordination considering fairness concerns," Journal of Management Sciences in China, 2010.

[19] F. Zhang and J. Ma, "Research on the complex features about a dual-channel supply chain with a fair caring retailer," Communications in Nonlinear Science and Numerical Simulation, vol. 30, no. 1-3, pp. 151-167, 2016.

[20] Q.-H. Li and B. Li, "Dual-channel supply chain equilibrium problems regarding retail services and fairness concerns," Applied Mathematical Modelling: Simulation and Computation for Engineering and Environmental Systems, vol. 40, no. 15-16, pp. 7349-7367, 2016.

[21] D.-P. Wang, Q.-Y. Shang, and B.-Q. Zhang, "Research on the coordination of a dual-channel supply chain considering fairness Concern," in Proceedings of the 2017 International Conference on Management Engineering, Software Engineering and Service Sciences, ICMSS 2017, pp. 214-218, Wuhan, China, January 2017.

[22] T. Zhang and X. Wang, "The impact of fairness concern on the three-party supply chain coordination," Industrial Marketing Management, 2018.

[23] D. Rand, "Exotic phenomena in games and duopoly models," Journal of Mathematical Economics, vol. 5, no. 2, pp. 173-184, 1978.

[24] T. Puu, "The chaotic duopolists revisited," Journal of Economic Behavior \& Organization, vol. 33, no. 3-4, pp. 385-394, 2004.

[25] G. I. Bischi, C. Mammana, and L. Gardini, "Multistability and cyclic attractors in duopoly games," Chaos, Solitons \& Fractals, vol. 11, no. 4, pp. 543-564, 2000.

[26] Z. Sun and J. Ma, "Complexity of triopoly price game in Chinese cold rolled steel market," Nonlinear Dynamics, vol. 67, no. 3, pp. 2001-2008, 2012.

[27] T. Li and J. Ma, "Complexity analysis of the dual-channel supply chain model with delay decision," Nonlinear Dynamics, vol. 78, no. 4, pp. 2617-2626, 2014. 
[28] J. Ma and H. Wang, "Complexity analysis of dynamic noncooperative game models for closed-loop supply chain with product recovery," Applied Mathematical Modelling: Simulation and Computation for Engineering and Environmental Systems, vol. 38, no. 23, pp. 5562-5572, 2014.

[29] Q. Li and J. Ma, "Research on price Stackelberg game model with probabilistic selling based on complex system theory," Communications in Nonlinear Science and Numerical Simulation, vol. 30, no. 1-3, pp. 387-400, 2016.

[30] Y. Huang, L. Liu, and E. Qi, "The dynamic decision in riskaverse complementary product manufacturers with corporate social responsibility," Kybernetes. The International Journal of Cybernetics, Systems and Management Sciences, vol. 45, no. 2, pp. 244-265, 2016.

[31] Y. Zheng, Y. Nian, and D. Wang, "Controlling fractional order chaotic systems based on Takagi-Sugeno fuzzy model and adaptive adjustment mechanism," Physics Letters A, vol. 375, no. 2, pp. 125-129, 2010.

[32] T. Li, J. Ma, and L. Sun, "Complexity uncertainty analysis of dynamic in a dual-channel energy supply chain model with heterogeneous retailers," Mathematical Problems in Engineering, vol. 2015, Article ID 562158, 10 pages, 2015.

[33] A. E. Matouk, A. A. Elsadany, and B. Xin, "Neimark-Sacker bifurcation analysis and complex nonlinear dynamics in a heterogeneous quadropoly game with an isoelastic demand function," Nonlinear Dynamics, vol. 89, no. 4, pp. 2533-2552, 2017.

[34] R. Wu and R. A. Van Gorder, "Nonlinear dynamics of discrete time multi-level leader-follower games," Applied Mathematics and Computation, vol. 320, pp. 240-250, 2018.

[35] J. Ma and J. Zhang, "Price game and chaos control among three oligarchs with different rationalities in property insurance market," Chaos: An Interdisciplinary Journal of Nonlinear Science, vol. 22, no. 4, Article ID 043120, 2012. 


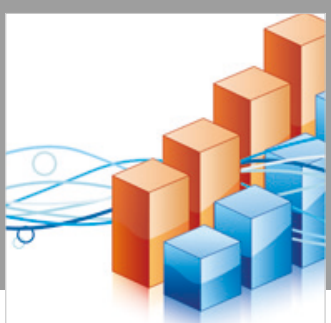

Advances in

Operations Research

\section{-n-m}
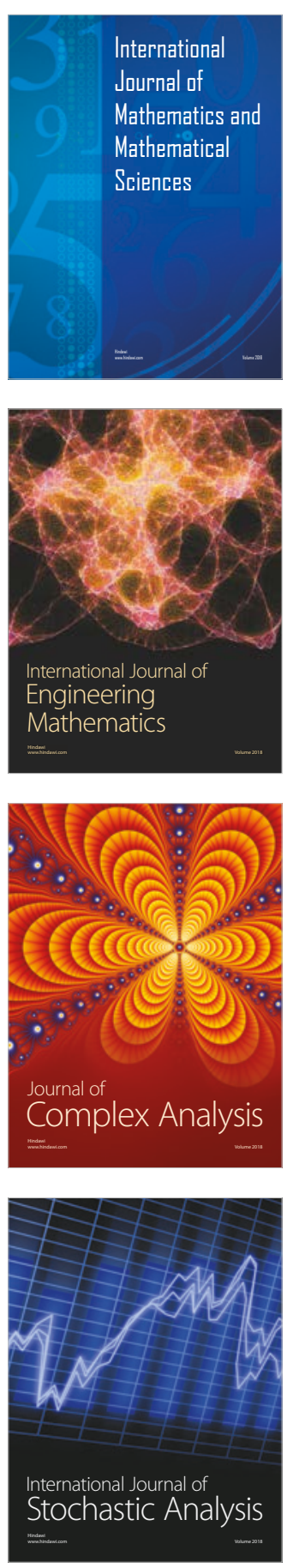
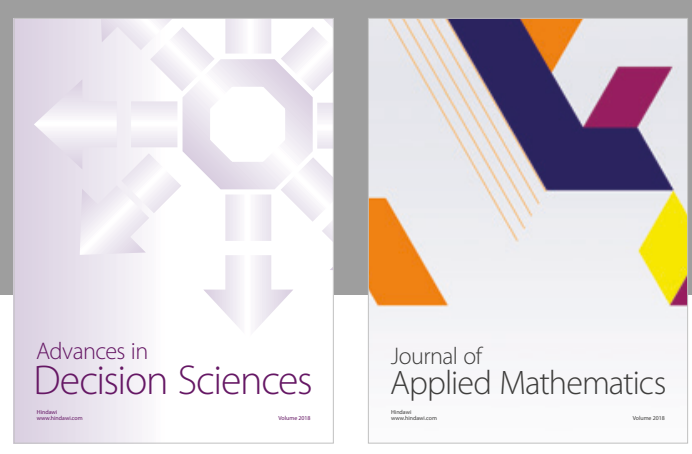

Journal of

Applied Mathematics
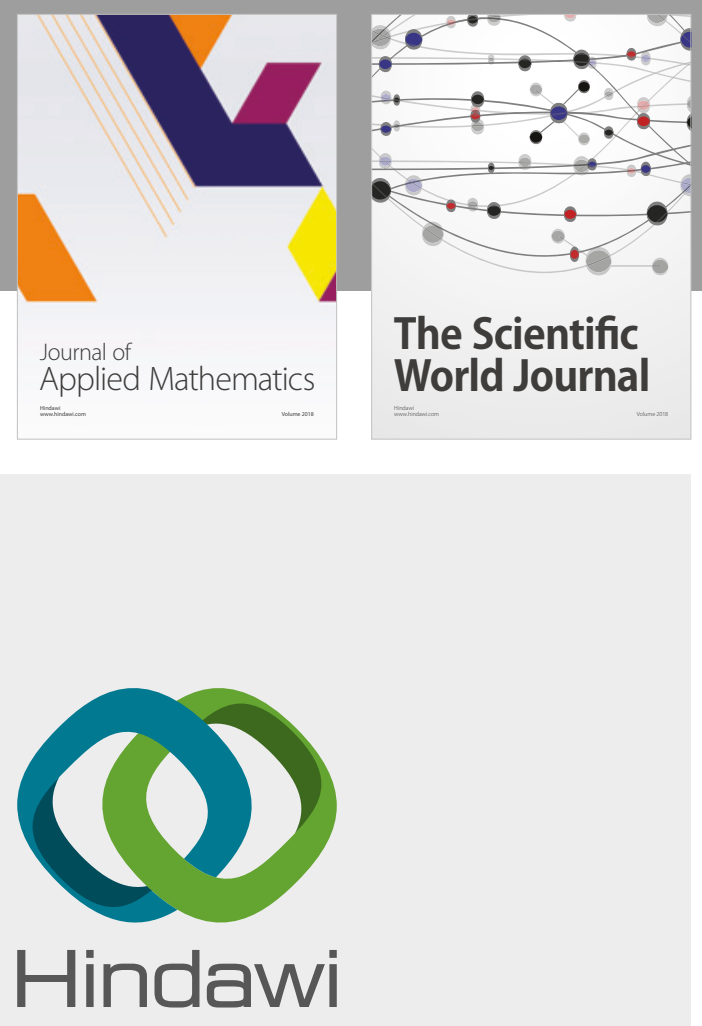

Submit your manuscripts at

www.hindawi.com

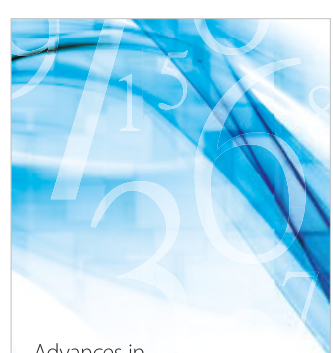

Advances in
Numerical Analysis
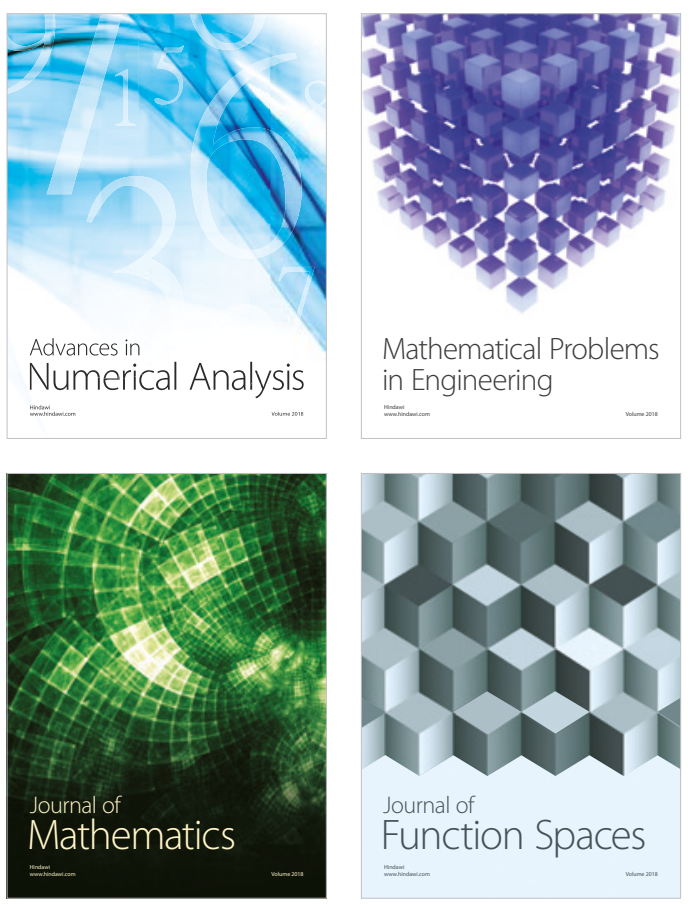

Mathematical Problems in Engineering

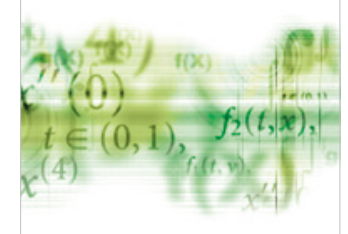

International Journal of

Differential Equations

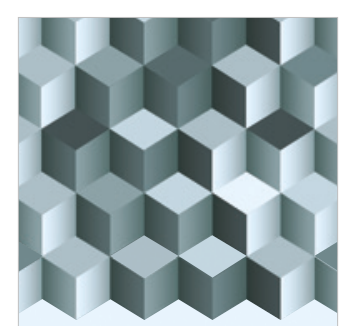

Journal of

Function Spaces
The Scientific

World Journal

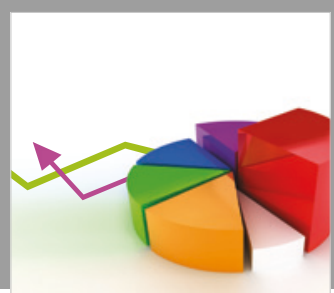

Journal of

Probability and Statistics
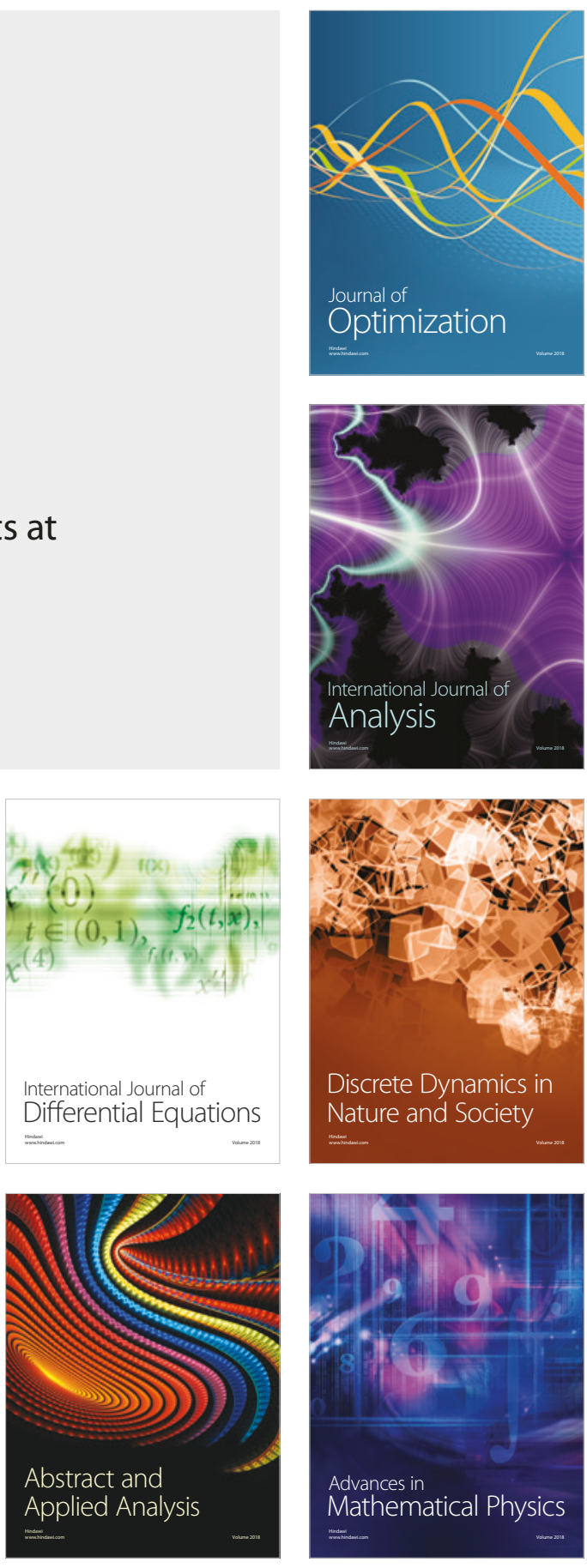